\title{
EVIDENCE FOR A SOLAR FLARE CAUSE OF THE PLEISTOCENE MASS EXTINCTION
}

\author{
Paul A LaViolette \\ The Starburst Foundation, 1176 Hedgewood Lane, Niskayuna, New York 12309, USA. Email: starburstfound@aol.com.
}

\begin{abstract}
The hypothesis is presented that an abrupt rise in atmospheric radiocarbon concentration evident in the Cariaco Basin varve record at 12,837 $\pm 10 \mathrm{cal}$ yr BP, contemporaneous with the Rancholabrean termination, may have been produced by a super-sized solar proton event (SPE) having a fluence of $\sim 1.3 \times 10^{11}$ protons $/ \mathrm{cm}^{2}$. A SPE of this magnitude would have been large enough to deliver a lethal radiation dose of at least 3-6 Sv to the Earth's surface, and hence could have been a principal cause of the final termination of the Pleistocene megafauna and several genera of smaller mammals and birds. The event time-correlates with a large-magnitude acidity spike found at $1708.65 \mathrm{~m}$ in the GISP2 Greenland ice record, which is associated with high $\mathrm{NO}^{-3}$ ion concentrations and a rapid rise in ${ }^{10} \mathrm{Be}$ deposition rate, all of which are indicators of a sudden cosmicray influx. The depletion of nitrate ions within this acidic ice layer suggests that the snowpack surface at that time was exposed to intense UV for a prolonged period, which is consistent with a temporary destruction of the polar ozone layer by solar cosmic rays. The acidity event also coincides with a large-magnitude, abrupt climatic excursion and is associated with elevated ammonium ion concentrations, an indicator of global fires.
\end{abstract}

\section{INTRODUCTION}

The Late Pleistocene megafaunal extinction ended abruptly about 12,900 yr ago. One distinctive feature is its terminal nature wherein extinct species were not replaced with new genera (Martin 1967). This circumstance contrasts with the rest of the Pleistocene during which there was a more or less orderly replacement of the old by new genera. Guilday (1967) compares this terminal event with the extinction of the dinosaurs at the end of the Cretaceous. Both events involved differential extinctions, large land animals (greater than $25-50 \mathrm{~kg}$ adult body weight) being primarily affected with the smaller vertebrates and the plant kingdom being in general relatively unaffected.

The cause of the Pleistocene mass extinction has for a long time been a mystery. Martin (1967) had proposed that, in North America, it was caused by the arrival of Paleolithic hunters immigrating via a land bridge that connected North America with Siberia during the ice age. However, this overkill hypothesis does not explain why the extinction took place also in Europe and Siberia. It also does not account for the simultaneous disappearance of 10 genera of birds (Grayson 1977) nor for the demise of many relatively young, tender mammoths in the San Pedro Valley without any sign of Clovis impact (Haynes 2006).

Others such as Vereshchagin (1967), Slaughter (1967), and Guilday (1967) have offered the alternative explanation that the disappearance could be attributed to the changes in climate that took place near the end of the ice age. However, Edwards (1967) points out that climatic change could not have accounted for these extinctions since abrupt changes have occurred in a cyclic manner throughout the Pleistocene without having any particularly pronounced effects on animal life. Also, Mehringer (1967) notes that there were no major barriers to migration into favorable habitats that might account for the extinction.

More recently, Firestone et al. $(2006,2007)$ report that an approximately 5 -cm-thick sediment layer overlying the termination boundary for the extinct Pleistocene megafauna as well as the Clovis Paleoindian occupational surface, and which they term the "YDB layer," contains high concentrations of extraterrestrial (ET) material indicators such as magnetic microspheres, iridium, nickel, nanodiamonds, and He-rich fullerenes. This led them to suggest that this extraterrestrial material was deposited by the impact or aerial explosion of one or more large comets (1-500 km diameter range), which caused the extinction of the Pleistocene megafauna and triggered a climatic cooling that initiated the Younger Dryas (YD). 
This comet hypothesis, however, faces a number of difficulties. First, no impact crater has been identified. Also, Melott et al. (2010) note that a comet of the size proposed by Firestone et al. (2007) should have produced a nitrate signal about $10^{5}$ fold larger than the highest $\mathrm{NO}_{3}{ }^{-}$concentrations observed in the GISP2 ice record and that the observed absence of such a large signal effectively rules out the YD comet impact scenario. Ice-core nitrate evidence also rules out the alternative scenario proposed by Napier (2010) that the Earth intercepted debris from a short-period comet resulting in $\sim 10^{4}$ Tunguska-like impacts. Such a meteor storm would have produced a total nitrate signal over $10^{3}$ fold greater than the largest nitrate peak observed in the YD section of the polar ice record.

The claim that high concentrations of iridium are present in the YDB layer is still a matter of controversy. Beets et al. (2008) have reported discovering extraterrestrial osmium in a Belgian sediment sample close to the Allerød/YD transition. Also, Mahaney et al. (2010) have reported high levels of the platinum group elements (PGEs) ruthenium and rhodium together with glassy carbon spherules and magnetic microspheres in a carbon-rich correlative YD layer in the Venezuelan Andes. In addition, Kurbatov et al. (2010) report finding a 270,000-fold increase in nanodiamond abundance relative to adjacent ice samples, which occurs in a $15-\mathrm{cm}$ ice section spanning the first $160 \mathrm{yr}$ of the YD. However, other groups, such as Paquay et al. (2009), Surovell et al. (2009), and Haynes et al. (2010), failed to find elevated concentrations of PGEs in YDB sediments using mass spectrometry analysis. Firestone et al. (2010) contend that the Murray Springs, Arizona, iridium results of Haynes et al. confirm their earlier ET findings.

Nevertheless, high concentrations of such ET indicators, if present at the YD boundary, do not uniquely imply a cometary impact origin. Fullerenes and nanodiamonds have both been found in carbonaceous chondrites and in interplanetary dust particle aggregates (Rietmeijer 2006). Also, Tian et al. (2011), who found large numbers of nanodiamonds in a black YD boundary layer from Lommel, Belgium, find no evidence that they were formed through a comet impact shock process. Cosmic microspheres also are known to be present in space, being found in the Earth's atmosphere at high altitudes and also on the Moon (Parkin et al. 1977). Also, ${ }^{3} \mathrm{He}$ is a common component of interplanetary dust particles, being implanted during their exposure in space to the solar wind. So the presence of elevated levels of ${ }^{3} \mathrm{He}$ in early YD sediments could just as well be attributed to a sudden influx of a large amount of cosmic dust.

The radiocarbon and cosmogenic Be evidence examined here suggests that the mass extinction had a solar cause. Several studies indicate that toward the end of the ice age the Sun was far more active than it is today. Zook et al. (1977) studied solar flare tracks etched in lunar rock micrometeorite craters and concluded that around $16 \mathrm{kyr}$ ago the average solar cosmic-ray intensity was 50 times higher than at present, declining to 15 times higher by $12 \mathrm{kyr} \mathrm{BP}$, and eventually reaching the present activity level. Elevated ${ }^{14} \mathrm{C}$ concentrations found in the surfaces of lunar rocks also indicate that for a period of $5000 \mathrm{yr}$ prior to $12 \mathrm{kyr} \mathrm{BP}$, the Moon was being exposed to a solar cosmic-ray flux averaging 30 times higher than the present flux (Zook 1980). Jull et al. (1999) have measured the concentration of ${ }^{14} \mathrm{C}$ versus depth in lunar rock 68815 and several lunar cores and found the levels to be elevated, consistent with a $25 \%$ elevation of the cosmic-ray exposure (solar plus galactic) over the past $\sim 30,000$ yr.

LaViolette $(1983,1985,1987,1990,2005)$ attributed this elevated solar activity to the entry of large quantities of dust and gas into the solar system and proposed that excessively large solar cosmic-ray events were a primary cause of the Pleistocene megafaunal extinction. ${ }^{14} \mathrm{C}$ data from the Cariaco Basin ocean sediment record as well as nitrate ion data from the Greenland ice core strengthen this conclusion. They suggest that one or more solar proton events occurring near the beginning of the 
Younger Dryas were sufficiently large to have produced radiation levels at the Earth's surface fatal for unprotected mammalian species.

\section{ELEVATED SOLAR ACTIVITY AT THE BEGINNING OF THE YOUNGER DRYAS}

The Cariaco Basin varved ocean sediment record located off the coast of Venezuela shows that ${ }^{14} \mathrm{C}$ abundance excess $\left(\Delta^{14} \mathrm{C}\right)$ in these sediments underwent a $65 \%$ rise relative to the ${ }^{14} \mathrm{C}$ trend line during the first $200 \mathrm{yr}$ of the YD, between 12,957 and 12,760 varve yr BP, synchronous with a 160-yrlong climatic cooling between 12,957 to 12,795 varve yr BP; see Figure 1 (Hughen et al. 2000). ${ }^{1}$ This ${ }^{14} \mathrm{C}$ excess is the largest in the Cariaco Basin record as far back as 15,000 cal yr BP and is also seen in sedimentary records from various locations around the world. This was preceded by a $30 \%$ $\Delta^{14} \mathrm{C}$ rise, which is registered between 13,450 and 13,250 cal yr BP and which correlates with the onset of the Intra Allerød Cold Peak (IACP).

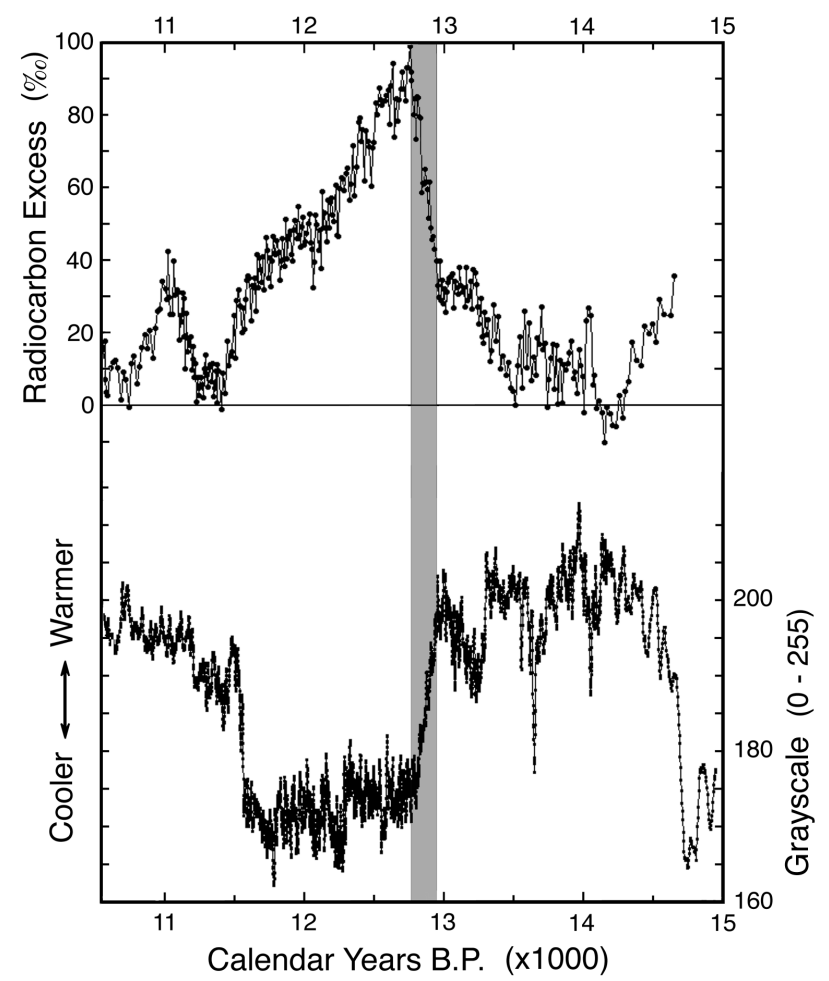

Figure 1 Radiocarbon abundance excess relative to the trend line value for the Cariaco Basin sediment core (upper profile) compared to the core's grayscale climate profile (lower profile). Higher grayscale values indicate warmer temperatures. Data is from Hughen et al. (2000).

Although part of the Cariaco Basin ${ }^{14} \mathrm{C}$ excess is likely due to a climatically induced change in the amount of old carbon present in the western subtropical Atlantic reservoir, a major portion of this excess appears to reflect a real increase in the atmospheric ${ }^{14} \mathrm{C}$ production rate. McManus et al.

${ }^{1}$ The remainder of the paper will adopt the Cariaco Basin chronology and refer to Cariaco Basin varve years as calendar years (cal yr). 
(2004) have charted changes in ${ }^{231} \mathrm{~Pa} /{ }^{230} \mathrm{Th}$ ratio in a core from the Bermuda rise as an indicator of the rate of meridional overturning circulation $(\mathrm{MOC})$ and find that there was a partial decrease in $\mathrm{MOC}$ at the onset of the Younger Dryas (YD) cooling. Presuming that a correlation might exist between MOC and ${ }^{14} \mathrm{C}$, Stocker and Wright (1996) computer simulated the YD $\Delta{ }^{14} \mathrm{C}$ rise but were able to attribute only half of the overall rise to a reduction in MOC. Also, Muscheler et al. (2000) used ${ }^{10} \mathrm{Be}$ deposition rates determined from analysis of GISP2 Greenland ice (Alley et al. 1997; Finkel and Nishizumi 1997) to model the atmospheric ${ }^{14} \mathrm{C}$ production rate at the end of the ice age. They concluded that the $\Delta^{14} \mathrm{C}$ increase at the onset of the YD is due partly to an increase in the cosmogenic production of atmospheric ${ }^{14} \mathrm{C}$ and partly to a reduction in old carbon entering surface waters due to a reduction in North Atlantic Deep Water formation.

Strong evidence for possible solar involvement in causing the $\mathrm{YD}{ }^{14} \mathrm{C}$ rise may be discerned from a close examination of the Cariaco Basin ${ }^{14} \mathrm{C}$ data. This shows that the rise in ${ }^{14} \mathrm{C}$ concentration at the beginning of the YD was punctuated by several spurts or sudden jumps (see arrows in Figure 2a). In terms of the rate of ${ }^{14} \mathrm{C}$ rise per year, 4 out of the 5 large spurts from 14.5 to $11.5 \mathrm{kyr}$ BP occur at the beginning of the YD. The Cariaco Basin varve chronology dates them at 12,973 $\pm 10,12,904 \pm 10$, $12,837 \pm 10$, and $12,639 \pm 10 \mathrm{cal} \mathrm{yr} \mathrm{BP}$. It is worth noting that they are spaced from one another by multiples of the Hale solar cycle period of $22.2 \pm 2 \mathrm{yr}$, that is, by $69 \pm 9,67 \pm 9$, and $198 \pm 9 \mathrm{yr}$, or 3 and 9 Hale cycles ( $\sim 67 \mathrm{yr}$ and $\sim 200 \mathrm{yr}$ ). The error assigned to the relative placement of these peaks mainly reflects the fact that each ${ }^{14} \mathrm{C}$ sample is an average of 8 to $12 \mathrm{yr}$ in the Cariaco Basin varve record. The finding that the timing of these events conforms to the solar cycle period favors the interpretation that these spurts reflect real increases in atmospheric ${ }^{14} \mathrm{C}$ and are not chance artifacts of the ${ }^{14} \mathrm{C}$ measurement process. One possible interpretation is that they register very large-magnitude SPEs that were generated at a time when the Sun was discharging super-sized coronal mass ejections (CMEs).

The $2{ }^{14} \mathrm{C}$ spurts at 12,837 and $12,639 \mathrm{cal}$ yr BP are the largest seen in the Cariaco Basin record. The first registers a $20 \%$ rise between 2 successive 8 -yr sampling intervals and the second registers a $20 \%$ rise between 2 successive 11 -yr sampling intervals. The time interval of $198 \pm 9 \mathrm{yr}$ between them is of particular interest because it approximates the Suess (de Vries) cycle of $\sim 200 \mathrm{yr}$, which is believed to be one of the most prominent solar cycles. The Suess cycle is a dominant cycle during the Holocene and has also been identified at $205 \pm 5 \mathrm{yr}$ in GRIP ice-core ${ }^{10} \mathrm{Be}$ data from $25-50 \mathrm{kyr}$ BP (Wagner et al. 2001), at 197 yr in GISP2 Wisconsonian dust data (Ram and Stolz 1999), and in the ${ }^{14} \mathrm{C}$ record (Stuiver and Kra 1986; Beer 2000).

Close to the time of the $12,837 \mathrm{yr}$ BP ${ }^{14} \mathrm{C}$ spurt, the GISP2 Summit Greenland ice-core record registers a prominent peak in ${ }^{10} \mathrm{Be}$ deposition rate (see solid line in Figure 2c). Atmospheric ${ }^{10} \mathrm{Be}$, like ${ }^{14} \mathrm{C}$, is currently produced primarily by the intergalactic cosmic-ray proton background radiation that strikes the Earth's atmosphere, but large amounts are also produced during SPEs (McCracken et al. 2001a). It is unlikely that this ${ }^{10} \mathrm{Be}$ peak was due to a change in geomagnetic screening since geomagnetic field intensity has been found to have had a minimal effect in modulating ${ }^{10} \mathrm{Be}$ production in high-latitude regions such as Greenland (Beer et al. 1984). The ${ }^{10} \mathrm{Be}$ deposition rate values plotted here are calculated from the ${ }^{10} \mathrm{Be}$ concentration values of Finkel and Nishiizumi (1997) using the ice accumulation rate data of Alley et al. (1997). Dates assigned to the samples in this profile are based on the Cariaco Basin varve chronology.

The Cariaco Basin varve chronology has been synchronized with the Holocene dendrochronology scale and is believed to be accurate to $\pm 10 \mathrm{yr}$ (Hughen et al. 2000). It should provide a more reliable time indicator over the YD interval than the Greenland ice-core chronology since the ice sheet was 


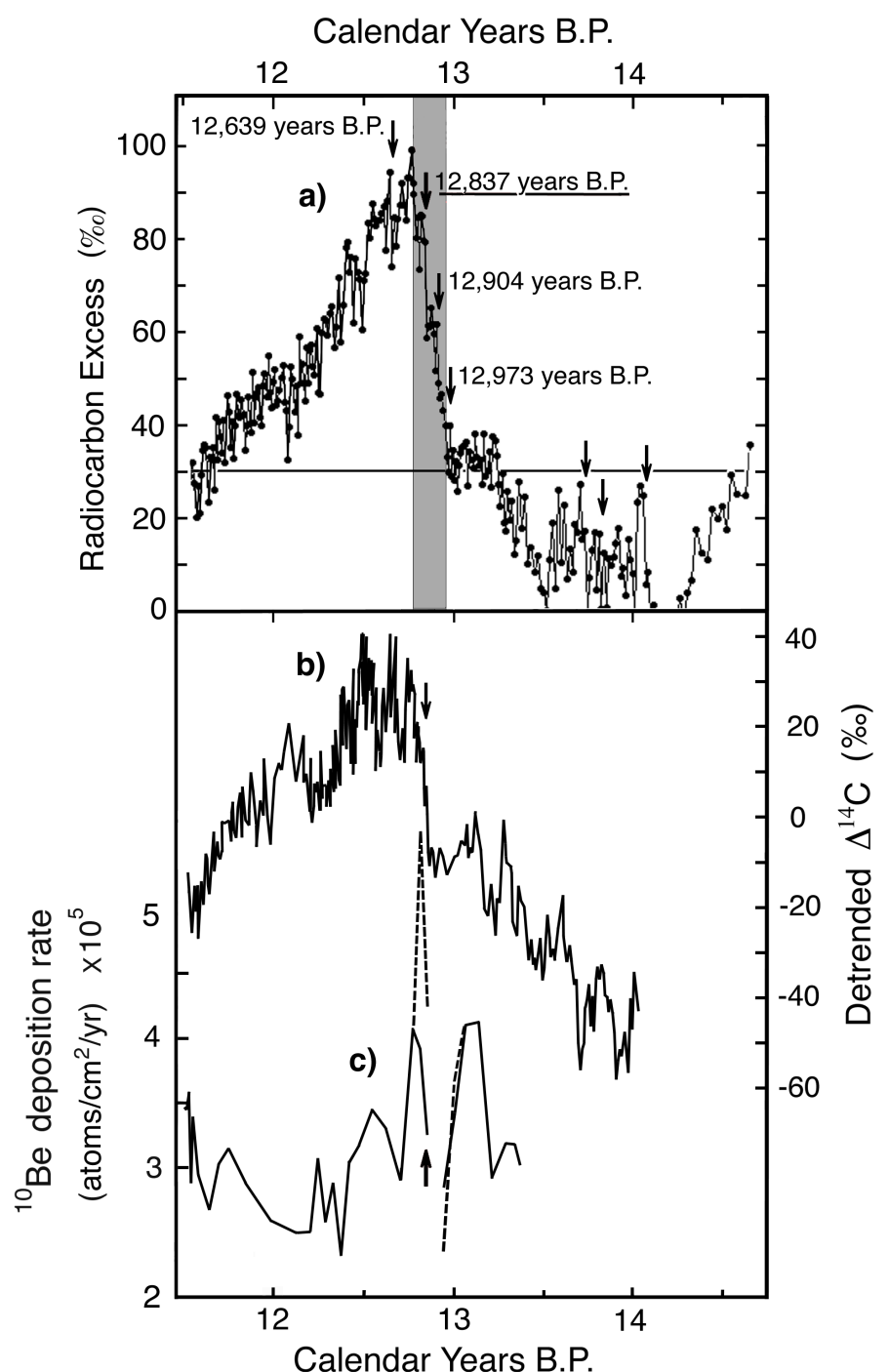

Figure 2 a) ${ }^{14} \mathrm{C}$ excess relative to trend line as seen in a Cariaco Basin sediment core. Arrows indicate times of large spurts in ${ }^{14} \mathrm{C}$ production, indicative of dates of SPEs. Data is from Hughen et al. (2000). b) ${ }^{14} \mathrm{C}$ excess relative to trend line as seen in the floating Late Glacial Pine dendrochronology record (Hua et al. 2009) matched to the GISP2 ice-core ${ }^{10} \mathrm{Be}$ deposition rate profile shown in (c). c) ${ }^{10} \mathrm{Be}$ deposition rate based on the ${ }^{10} \mathrm{Be}$ concentration data of Finkel et al. (1997) adjusted using the ice accumulation rate data of Alley et al. (1997) and dated according to the Cariaco Basin chronology (solid line). ${ }^{10} \mathrm{Be}$ deposition rate based on accumulation rates inferred from applying the Cariaco Basin chronology (dashed line).

subject to melting during particularly warm YD intervals. The Cariaco Basin chronology is here transferred to the GISP2 ice record by matching up major climatic excursions evident in the GISP2 oxygen isotope profile with similar excursions in the Cariaco Basin grayscale profile. Figure 3 illustrates this matching over the early YD and late Allerød portion of the Cariaco Basin grayscale profile. 


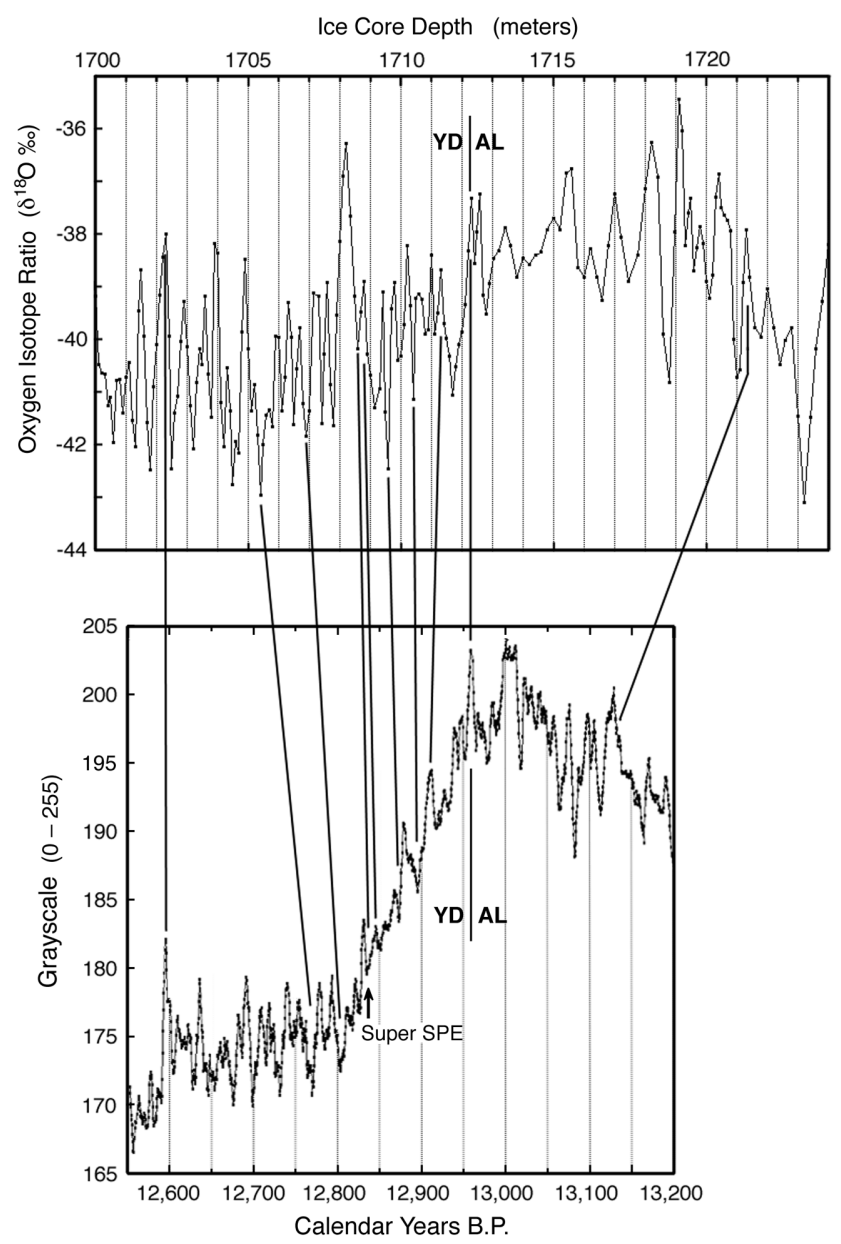

Figure 3 Correspondence between the Cariaco Basin grayscale climate profile (lower graph) and the GISP2 oxygen isotope profile (upper graph), allowing the Cariaco Basin varved chronology to be matched to GISP2 ice-core depth scale. Data courtesy of Hughen et al. (2000) and Stuiver and Grootes (2000).

Table 1 shows how associated Cariaco Basin varve dates correspond with ice-core meter depths for these features seen in the GISP2 and NGRIP Greenland ice-core records. The bracketed GISP2 depths are interpolations. The standard GICC05 Greenland ice-core chronology (Rasmussen et al. 2008) is shown for comparison in the last column.

Varve dating of the Cariaco Basin grayscale profile shows the Younger Dryas as having lasted for a period of $1414 \mathrm{yr}$, whereas the GISP2 ice-core chronology of Alley et al. (1997), which is based on counts of annual layers in the ice, shows the Younger Dryas as having lasted only about $1281 \mathrm{yr}$, or $1246 \mathrm{yr}$ in the GICC05 ice-core chronology. The 156- and 168-yr shortfalls in the Greenland chronologies may be attributed to a possible loss through melting of about $11-12 \%$ of the ice accumulated during the YD period. This could have occurred during the mid- and late phase of the YD when the oxygen isotope ratio reached above the $-38 \%$ Allerød level on numerous occasions, as seen in high-resolution isotope profiles. 
Table 1 Depth-time marker horizons used in transferring the Cariaco Basin chronology to the Summit, Greenland GISP2, and NGRIP oxygen isotope profiles.

\begin{tabular}{lllll}
\hline $\begin{array}{l}\text { Climatic } \\
\text { boundaries }\end{array}$ & $\begin{array}{l}\text { Cariaco } \\
\text { Basin } \\
(\mathrm{yr} \text { BP })\end{array}$ & $\begin{array}{l}\text { GISP2 } \\
\text { mid-depth } \\
(\mathrm{m})\end{array}$ & $\begin{array}{l}\text { NGRIP } \\
\text { mid-depth } \\
(\mathrm{m})\end{array}$ & $\begin{array}{l}\text { GICC05 } \\
\text { chronology } \\
\text { (yr BP) }\end{array}$ \\
\hline PB ends & 11,464 & 1664.0 & & \\
YD ends & 11,543 & 1676.17 & 1490.44 & 11,610 \\
Temp. min. & 11,547 & 1677.15 & 1491.45 & 11,630 \\
Temp. min. & 11,569 & 1678.25 & 1492.15 & 11,646 \\
Temp. min. & 11,783 & 1684.9 & & 11,877 \\
Temp. max. & 12,161 & 1688.7 & & 11,998 \\
Temp. max. & 12,450 & 1699.2 & & 12,367 \\
Temp. max. & 12,595 & 1702.25 & & 12,470 \\
Temp. min. & 12,770 & 1705.35 & & 12,591 \\
Temp. min. & $12,803.5$ & 1706.90 & 1520.45 & 12,645 \\
Temp. max. & $12,831.5$ & $(1708.45)$ & 1521.98 & 12,696 \\
Warming begins & 12,834 & $(1708.55)$ & 1522.08 & 12,700 \\
Acidity spike & 12,837 & 1708.65 & 1522.20 & 12,704 \\
Temp. max. & 12,846 & 1708.8 & 1522.35 & 12,710 \\
Temp. min. & 12,873 & 1709.55 & 1522.98 & 12,733 \\
Temp. min. & 12,895 & 1710.35 & 1523.78 & 12,742 \\
Temp. max. & 12,912 & 1711.25 & 1524.43 & 12,782 \\
YD begins & 12,957 & 1712.25 & 1526.9 & 12,856 \\
IACP ends & 13,133 & 1721.26 & & 13,039 \\
IACP begins & 13,300 & 1727.29 & & 13,203 \\
Temp. min. & 13,653 & 1762.2 & & 13,048 \\
\hline
\end{tabular}

The Cariaco Basin chronology projects accumulation rates for the GISP2 ice core that differ from those published by Alley et al. (1997) during the early YD. When the ${ }^{10} \mathrm{Be}$ deposition rate values are recalculated using ice accumulation rates inferred from the Cariaco Basin chronology, they appear as shown with the dashed line profile in Figure 2c, which has been adjusted so that both chronologies give the same ${ }^{10} \mathrm{Be}$ deposition rate value at a depth of $1717.4 \mathrm{~m}(13.06 \mathrm{kyr} \mathrm{BP})$. This causes the ${ }^{10} \mathrm{Be}$ deposition rate peak at $12.81 \mathrm{kyr} \mathrm{BP}$ to increase in magnitude and the ${ }^{10} \mathrm{Be}$ data point at 12.94 kyr BP to decrease in magnitude. So, the ${ }^{10} \mathrm{Be}$ deposition rate is now seen to rise more than $50 \%$ between the 12.94 kyr BP sample and the $12.85 \mathrm{kyr} \mathrm{BP}$ sample that spans the $12,837 \mathrm{yr} \mathrm{BP}{ }^{14} \mathrm{C}$ spurt, thus providing stronger support for the hypothesis that this part of the ice record registers the occurrence of a super SPE. The gap in the data between 12.87 and $12.91 \mathrm{kyr}$ BP is due to missing ${ }^{10} \mathrm{Be}$ data for the ice-core depth range $1709.5-1711 \mathrm{~m}$.

It is proposed that the $12,837 \mathrm{yr} \mathrm{BP}{ }^{14} \mathrm{C}$ spurt evident in the Cariaco Basin ocean sediment record and this ${ }^{10} \mathrm{Be}$ deposition rate peak that closely follows it were both produced by one or more largemagnitude SPEs. Finkel and Nishiizumi (1997) analyzed 1.6-m ice-core sections for their ${ }^{10} \mathrm{Be}$ data, which span relatively long intervals of 30-40 yr. Any large increase in ${ }^{10} \mathrm{Be}$ influx rate from a discrete SPE event would average out to a much lower value in the existing ${ }^{10} \mathrm{Be}$ data. To properly represent this ${ }^{10} \mathrm{Be}$ rise, a more detailed stratigraphic analysis is needed in this part of the ice core.

The detrended $\Delta^{14} \mathrm{C}$ profile for the floating Late Glacial Pine (LGP) dendrochronology record taken from the data of Hua et al. (2009) is compared in Figure 2, profile b, with the detrended Cariaco Basin $\Delta^{14} \mathrm{C}$ profile in (a). This floating LGP profile is anchored to the Cariaco Basin chronology by correlating its sharp $\Delta^{14} \mathrm{C}$ rise with the prominent ${ }^{10} \mathrm{Be}$ deposition rate peak plotted in Figure 2, pro- 
file c. ${ }^{2}$ Compared to the Cariaco profile, the LGP profile shows a smaller ${ }^{14} \mathrm{C}$ excess of $\sim 40 \%$ occurring at the beginning of the YD. Nevertheless, it does display a sharp rise in $\Delta^{14} \mathrm{C}$ in coincidence with the sharp rise in ${ }^{14} \mathrm{C}$ excess evident in the Cariaco Basin record at 12,837 cal yr BP. At the time of this event, $\Delta{ }^{14} \mathrm{C}$ in the LGP record increased $17 \%$ within a 20 -yr timespan, reaching an overall increase of $26 \%$ after an additional 10 yr. By comparison, in the Cariaco Basin profile, $\Delta^{14} \mathrm{C}$ increased 20\%o within an 8-yr timespan and reached an overall increase of 26\%o within the space of $25 \mathrm{yr}$ (3 sampling intervals). A second $\Delta^{14} \mathrm{C}$ peak is seen to follow this primary peak in the LGP record. This matches approximately with the date of the second major Cariaco Basin ${ }^{14} \mathrm{C}$ spurt at $12,639 \pm 10 \mathrm{cal}$ yr BP. The more minor ${ }^{14} \mathrm{C}$ spurts evident in the Cariaco Basin record at 12,973 \pm 10 and $12,904 \pm 10 \mathrm{cal}$ yr BP do not correlate with any significant ${ }^{14} \mathrm{C}$ rise in the LGP profile, suggesting that the magnitude of those earlier spurts in the Cariaco Basin profile may have been exaggerated by a sudden reduction in old carbon entering ocean surface waters at the beginning of the YD.

\section{ASSESSING THE RADIATION HAZARD}

The solar proton event (SPE) that impacted during the February 1956 solar maximum is estimated to have produced an atmospheric $\Delta^{14} \mathrm{C}$ increase of only $0.16 \%$ (Usoskin et al. 2006), or $8 \%$ of the variation produced over the course of a typical solar cycle. By comparison, the initial $20 \%$ rise in ${ }^{14} \mathrm{C}$ concentration at the time of the $12,837 \mathrm{yr}$ BP spurt indicates the occurrence of a SPE that was at least 125 times more intense. Here, we are making the assumption that most or all of the spurt's $\Delta^{14} \mathrm{C}$ increase was due to atmospheric ${ }^{14} \mathrm{C}$ production with little or no contribution from changes in ocean circulation, which typically transpire over a much longer time period. This should be a safe assumption since the floating LGP dendrochronology record, which is less vulnerable to changes in ocean circulation, charts a comparable $\Delta^{14} \mathrm{C}$ increase at this time.

The February $1956 \mathrm{SPE}$ is estimated to have delivered a total particle fluence of $10^{9}$ protons $/ \mathrm{cm}^{2}$ (McCracken et al. 2001a). Hence, the 12,837 yr BP event would have delivered 125 times more, or on the order of $1.25 \times 10^{11}$ protons $/ \mathrm{cm}^{2}$. The full $26 \%$ rise in $\Delta^{14} \mathrm{C}$ occurring over a period of 2 decades would translate into a fluence of $1.6 \times 10^{11}$ protons $/ \mathrm{cm}^{2}$. The magnitude of the $12,639 \mathrm{yr} \mathrm{BP}$ spurt translates into a SPE having a fluence of about $1.25 \times 10^{11}$ protons $/ \mathrm{cm}^{2}$. Flares of such a large magnitude are not unusual from the astronomical perspective. For example, "superflares" ranging from $10^{2}$ to $10^{7}$ times the energy of the February 1956 solar flare have been observed to occur on nearby sun-like stars (Schaefer et al. 2000). Jull et al. (1999) state that the ${ }^{14} \mathrm{C}$ levels present in lunar rock 68815 , which are $25 \%$ higher than can be explained on the basis of the long-term average cosmic-ray exposure, could be accounted for by at least one large SPE having occurred in the past $10^{4}$ yr that was capable of delivering an integrated flux of $10^{13}$ protons $/ \mathrm{cm}^{2}$. The proposed SPE levels individually and collectively fall below this integrated flux level.

The magnitude of the ground-level radiation exposure that animals would have received would depend on the hardness of the SPE's spectrum. Harder-spectrum SPEs have greater fluences of highenergy cosmic rays, e.g. $>500 \mathrm{MeV}$, and are capable of deeper penetration through the atmosphere to deliver a higher ground-level radiation dose. The February 1956 SPE, which had a relatively hard

\footnotetext{
${ }^{2} \mathrm{Hua}$ et al. (2009) have also matched the detrended $\Delta{ }^{14} \mathrm{C}$ LGP profile to the same peak in the ${ }^{10} \mathrm{Be}$ deposition rate data of Finkel and Nishiizumi (1997). However, they date their ${ }^{10}$ Be profile using the GICC05 ice-core chronology with an applied -65 -yr correction, which instead dates the YD onset at $\sim 12,760$ corrected yr BP. Nevertheless, their chronology shows the sharp rise in the LGP $\Delta^{14} \mathrm{C}$ record as occurring $\sim 125 \mathrm{yr}$ after the $\mathrm{YD}$ onset, which is consistent with the Cariaco Basin chronology that shows the $12,837 \mathrm{yr} \mathrm{BP}{ }^{14} \mathrm{C}$ spurt in the Cariaco Basin record as similarly occurring $120 \mathrm{yr}$ after the YD onset.
} 
spectrum, was observed to produce a ground-level particle enhancement that was 50 times that of the cosmic-ray background measured at Leeds, UK (1 Gev rigidity cut-off). Foelsche (1974) estimates as an upper limit that this SPE would have delivered a radiation dose of $0.7 \mathrm{rads} / \mathrm{hr}$ at an altitude of $14 \mathrm{~km}$ at $60^{\circ}$ geomagnetic latitude. This is equivalent to about $1.2 \mathrm{rem} / \mathrm{hr}$ or $12 \mathrm{mSV} / \mathrm{hr}$, where 1 Sievert $(\mathrm{Sv})=100 \mathrm{rems}$. His radiation dose versus altitude plot projects a lower value at ground level of about $0.5 \mathrm{mSv} / \mathrm{hr}$ (or $\sim 0.25 \mathrm{mSv} / \mathrm{hr}$ for his lower-limit estimate), the dose reduction being due to the shielding effects of the atmosphere. If it had a comparable spectral hardness, the $12,837 \mathrm{yr}$ BP SPE would have delivered a dose rate $\sim 125$ fold larger than this, causing animals at sea level to accumulate as much as $3 \mathrm{~Sv}$ over a 50 -hr period. Here, we assume that the period of elevated cosmic-ray exposure continued for at least 2 days as it did during the 1859 Carrington event. Shortduration exposure to radiation doses exceeding $3.5 \mathrm{~Sv}$ are known to be lethal to humans (Epelman and Hamilton 2006) with 100\% fatalities (LD-100) occurring at around 4-6 Sv. LD-100 for most large mammals spans the range from 3 to $8 \mathrm{~Sv}$.

The ring current generated by the 1956 SPE was able to produce a $1 \%$ main phase decrease in geomagnetic field intensity (Dessler and Parker 1959). Consequently, ice age SPEs that were over 2 orders of magnitude stronger than this could have substantially weakened or overpowered the Earth's field and allowed the full intensity of their cosmic-ray plasma to contact the Earth's atmosphere (LaViolette 1983, 1987). Since Foelsche's estimate assumes a $60^{\circ}$ geomagnetic latitude location, which today has a 1-Gev cut-off rigidity, the values projected for the 12,837 yr BP SPE should be revised upward considering that even mid-latitude regions would be left devoid of magnetosphere protection. It is probable, then, that the $12,837 \pm 10 \mathrm{cal}$ yr BP SPE could have delivered a radiation dose of substantially over $6 \mathrm{~Sv}$, which would have been lethal to large Pleistocene megafauna that were not sheltered from exposure. This radiation hazard therefore could have been a major cause of the Pleistocene mass extinction.

The geomagnetic excursion produced by the proposed super-sized SPE would be difficult to detect in the sedimentary record due to the event's brevity ( $\sim 1$ yr). Nevertheless, a study of Lake Erie sediments near Erieau, Ontario, does show that geomagnetic inclination was unstable during the ice age terminal period between about $13,000-10,500{ }^{14} \mathrm{C}$ yr BP $(15,450-12,550$ cal yr BP) (Creer et al. 1976).

\section{THE CONTEMPORANEOUS MASS EXTINCTION}

There is a question as to whether the megafaunal extinction was progressive, perhaps lasting several millennia, or whether it occurred all at once in a single catastrophic event. Meltzer and Mead (1985) have suggested that it progressed over several thousand years with most of the extinct megafauna disappearing at or prior to $11,000 \pm 100{ }^{14} \mathrm{C}$ yr BP or at or prior to $12,910 \pm 100 \mathrm{cal} \mathrm{yr} \mathrm{BP}$ in the Cariaco Basin chronology. Haynes (2008) proposes a slightly more recent cut-off date of 10,900 \pm 50 ${ }^{14} \mathrm{C}$ yr BP for the Rancholabrean termination, or $12,883 \pm 60$ cal yr BP in the Cariaco Basin ${ }^{14} \mathrm{C}$ chronology. The proposed 12,837 cal yr BP SPE falls within this date error limit. It should be acknowledged that there is some debate as to how ${ }^{14} \mathrm{C}$ dates should be converted to calendar dates for the early YD period.

Another useful time indicator are dates on Clovis Indian sites, a culture that existed just prior to the Rancholabrean termination. The Clovis cut-off date has been placed between 10,900 and $10,800{ }^{14} \mathrm{C}$ yr BP (Meltzer 2004; Waters and Stafford 2007). This is equivalent to the interval between 12,880 to 12,840 cal yr BP in the Cariaco Basin chronology. Hence, the Clovis culture end date immediately precedes the date of the proposed solar event. 
Another stratigraphic marker that is often referred to in connection with the megafaunal extinction is the black mat, a sediment layer ranging from black to gray to white in color found in the American Southwest covering the remains of extinct megafauna. It also overlies the YDB layer that Firestone et al. (2007) had proposed is enriched in ET debris. However, the age of the black mat does not "coincide with the abrupt onset of the Younger Dryas cooling," as stated by Firestone et al. Many black mat sites have base dates younger than the Younger Dryas (Haynes 2008). Also, Jull et al. (1999) have ${ }^{14} \mathrm{C}$ dated this stratum at the Murray Springs site and find it has a base date that ranges from 10,600 to $10,200{ }^{14} \mathrm{C}$ yr BP, hence between 12,750 and 11,850 Cariaco calendar yr BP.

Based on all of the above boundary dates (Rancholabrean, Clovis, and black mat), it is reasonable to place the abrupt termination of the Pleistocene megafauna as having occurred sometime within the first $200 \mathrm{yr}$ of the YD onset, or somewhere in the range of 12,950 to 12,750 calendar yr BP in the Cariaco Basin chronology. From a chronological standpoint, therefore, the proposed 12,837 cal yr BP SPE proves to be a good candidate as being the final cause of the megafaunal demise.

Grayson and Meltzer (2003) note that of the 35 mammal genera that disappeared in the extinction, only 16 can be shown to have lasted beyond $12,000{ }^{14} \mathrm{C}$ yr BP $(13,750 \mathrm{cal}$ yr BP). Thus, their findings suggest that over half of the genera became extinct 1 millennium prior to the Rancholabrean termination date. Faith and Surovell (2009), however, suggest that sampling error could explain why a majority of genera appear to have become extinct prior to $12,000{ }^{14} \mathrm{C}$ yr BP and that the megafaunal ${ }^{14} \mathrm{C}$ data is consistent with the hypothesis that all 35 species became extinct in the interval 10,000 to $12,000{ }^{14} \mathrm{C}$ yr BP, possibly even due to an abrupt and catastrophic event.

The proposed solar proton event (SPE) hypothesis, like the comet impact/explosion scenario of Firestone et al. (2007), is compatible with the occurrence of a single main catastrophic event. But, unlike the solitary-event comet scenario, the solar hypothesis also allows the possibility of the occurrence of multiple hazardous events of varying magnitude, as suggested by the presence of multiple ${ }^{14} \mathrm{C}$ spurts seen in both the Cariaco Basin and LGP dendrochronology records during the early $\mathrm{YD}$ as well as around the beginning of the IACP. ${ }^{3}$

\section{A SUPER SPE POSSIBLY RECORDED IN POLAR ICE}

By transferring the Cariaco Basin chronology to the GISP2 ice-core record, using the climate profile correlations given in Table 1, it is possible to locate a specific ice-core depth, $1708.65 \mathrm{~m}$, correlative with the $12,837 \mathrm{cal}$ yr BP spurt. At this correlated depth, the ice record registers a solitary largeamplitude acidity spike detected by means of the electrical conductivity measurement (ECM) technique. A high-resolution ECM plot of this acidity spike, charted at millimeter intervals along the icecore length, is shown in Figure 4 (Taylor et al. 1993). This same ECM event is also registered at a depth of $1657.51 \mathrm{~m}$ in the GRIP ice core and at $1522.2 \mathrm{~m}$ in the NGRIP ice core. It is unique in that a spike of such large magnitude is not seen for hundreds of years. It is the second largest acidity spike to occur during the Younger Dryas period. On the basis of the transferred Cariaco Basin chronology, it dates at $12,837 \pm 10$ cal yr BP, indicating that very acidic snows were being deposited

\footnotetext{
${ }^{3}$ If a super SPE had occurred as proposed and caused the ground-level cosmic-ray intensity to reach very high levels in certain geographic locations, this could explain why some megafaunal remains have anomalously young ${ }^{14} \mathrm{C}$ dates uncharacteristic of the strata age they are found in. That is, incident solar cosmic-ray protons could have generated thermal neutrons within animal tissues, which upon colliding with organic nitrogen could produce ${ }^{14} \mathrm{C}$ in situ in the animal remains (LaViolette 1983). Examples include the problematically young date of $2040 \pm 90{ }^{14} \mathrm{C}$ yr BP found for the terminal Pleistocene deposits in St. Petersburg, Florida, and also several mastodon remains in Michigan found to date at $\sim 6000{ }^{14} \mathrm{C}$ yr BP (Martin 1967). A young date of $5140 \mathrm{BC}$ has been found for a mastodon in Utah (Miller 1987) and a date of $4150 \mathrm{BC}$ has been found for one in Washtenaw, Michigan (Skeels 2002).
} 
around the time of the hypothesized 12,837 cal yr BP super SPE. The snows falling at the time of this event were so highly acidic that they increased the electrical conductivity of the ice 1000-fold compared with background conductivity levels prevailing before the event. Highly acidic snows would be an expected outcome if, as suggested earlier, the atmosphere had been exposed to a high flux of cosmic rays during a large-magnitude solar proton event.

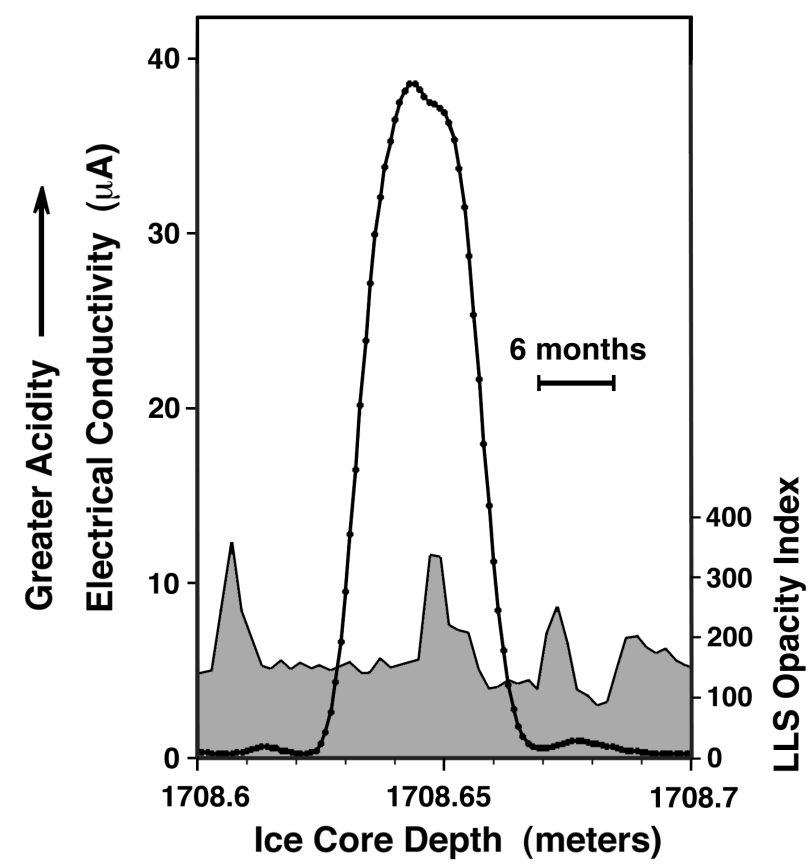

Figure 4 Ice-core conductivity profile from the GISP2 Greenland ice core indicating a period of high ice acidity possibly due to the arrival of a supersized SPE. Shown for comparison is the relative scattered light intensity indicating ice opacity. The event has been dated by adjusting the GISP2 ice-core chronology to the Cariaco Basin varve chronology. Data are from Taylor et al. (1993) and Ram et al. (1997).

The laser light scattering (LLS) data for this section of the ice core shows that ice opacity, an indicator of ice dust content, underwent a 100\% increase above background levels at the time of the ECM spike (Ram et al. 1997). This relatively modest LLS peak, which spans $\sim 1 \mathrm{~cm}$ of ice, likely represents the true width of this acidity spike, as compared with the 4-cm width for the ECM peak. The broader ECM width arises because the electrodes used in measuring ice-core conductivity are spaced $1 \mathrm{~cm}$ apart, and hence blur discrete acidity spike signals, making them look broader than they really are. Also, some peak broadening may be due to the tendency for the acid ions to diffuse through the snowpack or firn layers following their initial deposition. Based on the annual layer thickness of $3.3 \mathrm{~cm} /$ yr estimated for this portion of the ice core on the basis of the Cariaco Basin chronology, a 1-cm-wide ECM event would span $\sim 4$ months. Such a duration is consistent with the duration of the ECM signals for historical solar proton events. For example, the ECM signal for the Carrington event is seen in one GISP2 core to have a duration of 3 months (Dreschhoff and Zeller 1994).

Nitrate ions are produced when the atmosphere is exposed to cosmic rays. Thus, nitrate ion concentration spikes serve as good indicators of solar proton events (SPEs). McCracken et al. (2001a,b) 
have found that nitrate ion concentration spikes registered in the polar ice record during the period 1561 to 1950 correlate with major historical SPEs and that impulsive nitrate events serve as reliable indicators of large-fluence SPEs. The 12,837 yr BP ECM spike is seen to be associated with high nitrate ion concentrations in the GISP2 ice record, where the nitrate values plot 10-cm sample increments (Yang et al. 1995) - see Figure 5. The 200-ppb peak visible here is the highest nitrate level to occur during the entire Younger Dryas period, supporting the present suggestion that the 12,837 yr BP acidity peak records the occurrence of a very large-magnitude cosmic-ray event. A small-magnitude acidity spike measuring about $4 \%$ of the height of the $12,837 \mathrm{yr}$ BP ECM spike is seen at a depth of $1707.75 \mathrm{~m}$, dating to $\sim 12,819 \mathrm{cal} \mathrm{yr}$ BP. It too is seen to be associated with elevated nitrate ion concentrations, implying that it also may mark the occurrence of a SPE. It correlates with the 6\% rise $\Delta^{14} \mathrm{C}$ seen in the Cariaco Basin record to follow the $12,837 \mathrm{yr} \mathrm{BP}$ spurt.

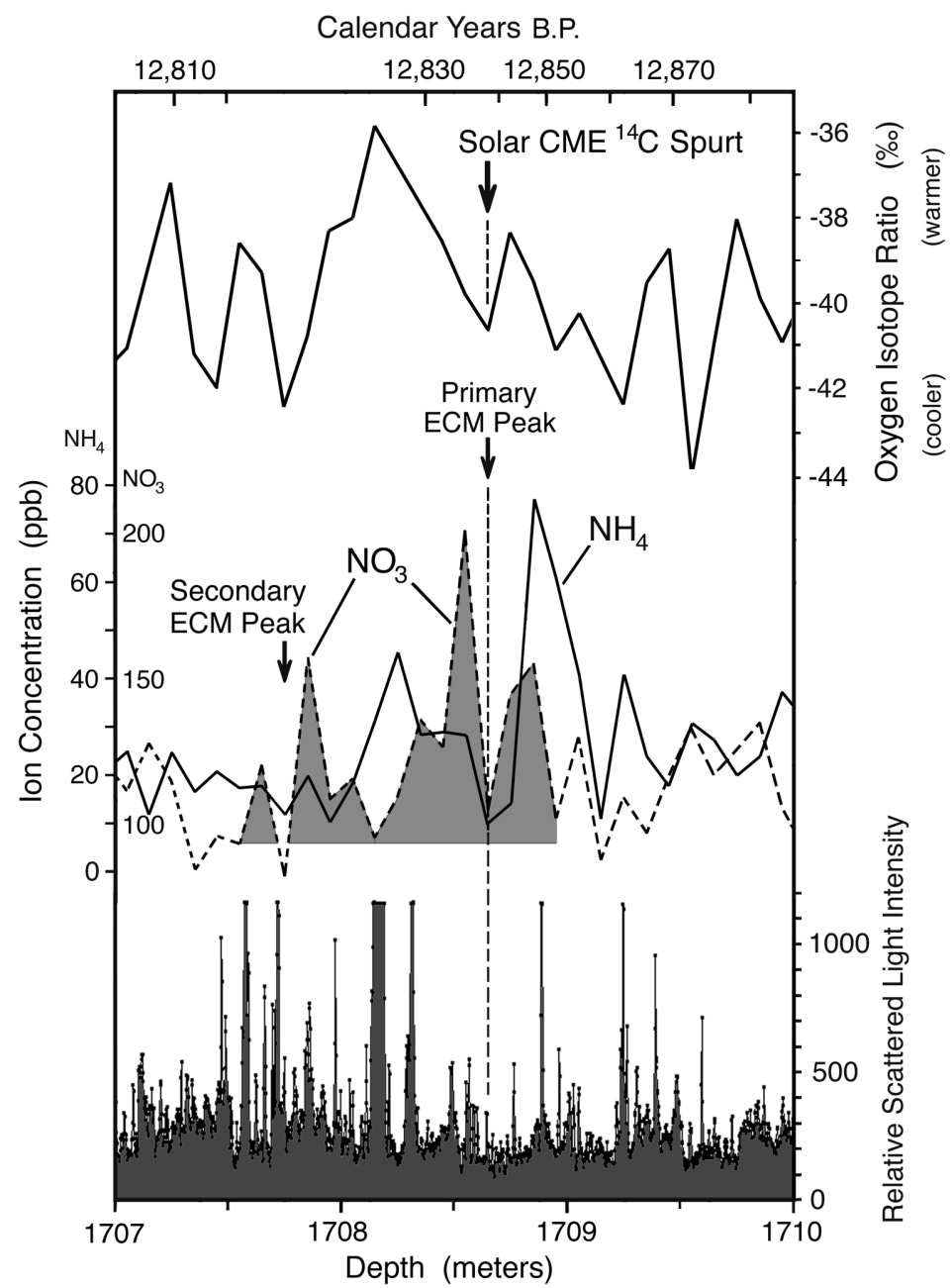

Figure 5 Nitrate and ammonium ion concentration in the GISP2 ice core (Yang et al. 1995; Taylor et al. 1996) compared to oxygen isotope ratio (upper profile) (Stuiver and Grootes 2000) and relative scattered light intensity (lower shaded profile) (Ram et al. 1997). The upper scale gives correspondence to the Cariaco Basin varve chronology. Large arrows indicate the depth of the GISP2 ECM spike and the correlated $12,837 \pm 10 \mathrm{cal} \mathrm{yr} \mathrm{BP}{ }^{14} \mathrm{C}$ spurt. Small arrows indicate the time of a subsequent small-magnitude ECM spike. 
The nitrate ion peaks associated with the $12,837 \mathrm{yr}$ BP acidity spike registers a cumulative, or "integrated," nitrate ion concentration amounting to $2900 \mathrm{ng} / \mathrm{cm}^{2}$ over the extent of its peak. The smaller event at 12,819 yr BP registers an integrated nitrate ion concentration of $\sim 1400 \mathrm{ng} / \mathrm{cm}^{2}$. Although this secondary SPE would have been smaller in magnitude than the proposed primary $12,837 \mathrm{yr}$ BP event, its radiation also would likely have been harmful to Pleistocene mammals.

The Carrington event of 1859, the largest solar proton event (SPE) to occur in modern times, is also reported to have produced a significant nitrate ion concentration spike in the Greenland ice record with a nitrate ion fallout lasting about 2.5 months (Dreschhoff and Zeller 1994). McCracken et al. (2001b) estimate that this SPE produced an integrated nitrate ion concentration of $750 \mathrm{ng} / \mathrm{cm}^{2}$ in Greenland ice. Based on this, they have calculated that it had a particle fluence of about $1.9 \times 10^{10}$ protons $/ \mathrm{cm}^{2}$ with energy $>30 \mathrm{MeV}$, hence a magnitude $\sim 20$ times greater than that of the February 1956 SPE. The integrated nitrate ion concentration for the 12,837 yr BP SPE is estimated to be at least 4-fold greater than that of the Carrington event.

Estimating the fluence of the $12,837 \mathrm{yr}$ BP super SPE by comparing its integrated nitrate ion concentration to that of historical SPEs could underestimate its true magnitude. Very large-magnitude SPEs produce $\mathrm{NO}_{\mathrm{x}}$ and $\mathrm{OH}$ ions in the mesosphere and stratosphere in sufficient quantities to destroy the Earth's polar ozone layer. This substantially increases the solar UV flux, which photolytically dissociates nitrate ions deposited in surface snows. Hence, the fraction of the nitrate ion flux that is ultimately preserved in the ice record is expected to be substantially lower for a super SPE than for historical SPEs of lesser magnitude. In addition, nitrate ions would be created not only by the SPE, but also by the coronal mass ejection that would follow it. So it is difficult to assess what fraction of the total nitrate signal would be attributable just to the SPE.

Field studies in Antarctica and Greenland have shown elevated $\mathrm{NO}_{\mathrm{x}}$ levels above sunlit snowpacks, implicating photochemical processes acting on the snowpack (Jones et al. 2000). Experiments conducted in polar regions have demonstrated that $\mathrm{NO}_{\mathrm{x}}$ is produced within the snowpack and released from its surface at a rate that varies with the UV diurnal cycle (Jones et al. 2000, 2001; Dibb et al. 2002). McCabe et al. (2005) have demonstrated in the laboratory that nitrate concentrations in ice decrease as much as 10 -fold when exposed to a 313 -nm UV photon flux of $\sim 0.35$ sun equivalent for up to 2 days. They propose that this occurs through the photolytic reactions:

$$
\begin{gathered}
\mathrm{NO}_{3}^{-}+h v+\mathrm{H}^{+} \rightarrow \mathrm{NO}_{2}+\mathrm{OH} \\
\mathrm{NO}_{3}{ }^{-}+h v \rightarrow \mathrm{NO}_{2}^{-}+\mathrm{O}\left({ }^{3} \mathrm{P}\right)
\end{gathered}
$$

Such photolytic reactions account for why contemporary surface snows contain up to $300 \mathrm{ppb}$ of nitrate, while concentrations $1 \mathrm{~m}$ below can range only from 20-80 ppb (Wolff 1995).

An indication that nitrate ions were substantially depleted at the time of both the 12,837 and 12,819 yr BP events is seen in the nitrate ion profile of Figure 5. Nitrate ion concentration is instead seen to peak immediately before and immediately after each ECM spike and to reach minimum values in coincidence with each acidity spike event. Arrows indicate where $\mathrm{NO}_{3}{ }^{-}$would have originally peaked at the time of snow deposition. This depletion suggests that both SPEs produced stratospheric nitrates in sufficient quantities to destroy the Earth's polar ozone layer. By comparison, SPEs that have occurred in recent decades, which were far smaller in magnitude, exhibit polar ice nitrate ion concentration peaks that occur in coincidence with their polar ice ECM spikes (Zeller and Dreschhoff 1995; McCraken et al. 2001a). In other words, because they had a much smaller effect in causing ozone layer depletion, solar UV would have been less able to photochemically deplete snowpack nitrate ions, leaving their ion peaks intact. 
The SPE that occurred on July 2000 (fluence $\sim 4 \times 10^{9}$ protons $/ \mathrm{cm}^{2}$ with energy $>30 \mathrm{MeV}$ ) was found to eliminate $9 \%$ of the ozone in the upper stratosphere and up to $70 \%$ in the middle mesophere over a period of several days in northern polar regions above $60^{\circ}$ geomagnetic latitude (Jackman et al. 2001). The 12,837 yr BP super SPE, which is estimated to have been 30 times larger than this, would have been able to deplete the Earth's ozone layer to a much greater extent and over a much more extended period of time than has been observed for recent lower-fluence SPEs. Given that the nitrate ion troughs present at the time of this acidity peak and the subsequent acidity event both span a period of several years, we may infer that the ozone depletion persisted for a comparable period of time. They may have created an ozone layer hole that reached even to mid-latitudes.

Destruction of the ozone layer at the time of the Younger Dryas super SPE is of particular interest from the standpoint of its effect on animal survivability. For example, Reid et al. (1976) have proposed that past mass extinction episodes could have been caused by SPEs that were sufficiently large to cause ozone depletion and allow UV radiation to reach lethal levels. They have suggested that this could account for the finding of Hays et al. $(1967,1969)$ and Hays $(1971)$ that mass extinctions tend to correlate with geomagnetic polarity reversals. Similarly, in the case of the 12,837 and $12,819 \mathrm{yr}$ BP SPEs, the expected elevation of the solar UV flux could have posed a serious biohazard in lower latitudes and could have been a major factor contributing to the demise of the megafauna.

The nitrates in surface snows would likely have become vertically displaced to deeper snow layers. Nitric oxides generated photolytically in surface snows would have migrated downward to invade lower snowpack strata where the $\mathrm{NO}_{\mathrm{x}}$ would have reacted with the elevated concentrations of $\mathrm{OH}$ present there to regenerate nitrate ions through the following cage reactions (Dubowski et al. 2001; McCabe et al. 2005):

$$
\begin{aligned}
& \mathrm{NO}+\mathrm{OH} \rightarrow \mathrm{NO}_{2}^{-}+\mathrm{H}^{+} \\
& \mathrm{NO}_{2}+\mathrm{OH} \rightarrow \mathrm{NO}_{3}^{-}+\mathrm{H}^{+}
\end{aligned}
$$

Such nitrate regeneration would have resulted in a redistribution of $\mathrm{NO}_{3}{ }^{-}$ions from the UV photolyzed high-acidity snow layer to layers deposited prior to the SPE's occurrence. This would explain why a large nitrate ion peak immediately precedes each acidity spike stratum.

During the period when the stratospheric ozone layer was depleted, $\mathrm{NO}_{2}$ concentrations in the mesosphere and stratosphere would have risen partly due to the near absence of the nitrate production reaction $\mathrm{NO}_{2}{ }^{-}+\mathrm{O}_{3} \rightarrow \mathrm{O}_{2}+\mathrm{NO}_{3}{ }^{-}$and partly through increased $\mathrm{NO}_{3}{ }^{-}$photolysis via reactions 1 and 2. Once the ozone layer had become reestablished, stratospheric reactions would have favored $\mathrm{NO}_{3}{ }^{-}$ ion production from the elevated concentrations of $\mathrm{NO}_{\mathrm{x}}$ precursors that had previously accumulated. This would have boosted the rate of $\mathrm{NO}_{3}{ }^{-}$ion precipitation from the stratosphere and mesosphere, thereby explaining the presence of the $\mathrm{NO}_{3}{ }^{-}$peaks that follow the 12,837 and $12,819 \mathrm{yr} \mathrm{BP}$ acidity events. This extended period of elevated rate of nitrate ion production and precipitation, which could have lasted for 2-4 yr after SPE impact, may be accounted for by a combination of both atmospheric chemistry effects and the time required for the ions to fall from the stratosphere and become incorporated as $\mathrm{HNO}_{3}$ in snow precipitation. Jackman et al. (1980) have found that it took $\sim 1 \mathrm{yr}$ for the atmosphere's ion concentrations to return to pre-event levels following the August 1972 SPE. So a several-year period of elevated nitrate ion deposition for these early-YD events does not seem unusual. During the period that followed the regeneration of the ozone layer, the UV influx would have reduced sufficiently to allow a greater percentage of the deposited nitrate ion to survive in the snowpack. 
The 12,837 and 12,819 yr BP ECM spikes are also found to coincide with moderate increases in sulfate ion concentration, 3- and 2-fold respectively. This is not unexpected. The high concentrations of $\mathrm{NO}_{\mathrm{x}}$ and $\mathrm{OH}$ radicals generated in the stratosphere by the SPE create condensation nuclei, which attach to sulfate aerosols and accelerate their deposition through a scavenging process (Shumilov et al. 1996; McCracken et al. 2001b). Such sulfate peaks have been observed in association with contemporary events such as the February 1956 SPE (Isaksson et al. 2001). This raises the concern that many ECM spikes seen in the ice-core record in association with sulfate peaks may have been mistakenly interpreted as volcanic events.

It is unlikely that the $12,837 \mathrm{yr} \mathrm{BP}$ acidity spike was due to a volcanic eruption for several reasons. First, no volcanic eruption is known to have occurred at that time. The Laacher See eruption has been dated by dendrochronology to have occurred $200 \mathrm{yr}$ prior to the onset of the YD cooling (Baales et al. 1999), over 3 centuries prior to this event. Also, the presence of large nitrate peaks in association with this ECM spike favor a SPE interpretation. For example, a study of ECM and nitrate ion data in GISP2 ice over the past 4 centuries shows that nitrate ion spikes are associated with known SPEs but not with historic volcanic eruptions (Dreschhoff and Zeller 1994). Considering the unique magnitude of this spike, its $10^{3}$-fold increase in acidity, and its time correlation to the $12,837 \mathrm{yr} \mathrm{BP}{ }^{14} \mathrm{C}$ spurt, a solar origin seems more likely.

Ammonium ion concentration, an indicator of biomass combustion, is also seen to peak around the time of the $12,837 \mathrm{cal} \mathrm{yr} \mathrm{BP}{ }^{14} \mathrm{C}$ event, reaching its highest value for the YD period (Taylor et al. 1996). Concentrations of formate and oxylate ion, also indicators of biomass combustion, reached high levels around this time as well (Legrand et al. 1992). The LLS data for the GISP2 ice core (Ram et al. 1997) registers a number of dark layers in this part of the ice record (see Figure 5, lower profile). Dark layers spanning about 4 and $7 \mathrm{~cm}$ of ice are seen to correlate with the ammonium concentration peak that follows the $12,837 \mathrm{yr}$ BP ECM spike and a dark layer spanning about $1 \mathrm{~cm}$ of ice is seen to correlate with the ammonium peak that precedes this ECM spike.

Some report sedimentary evidence of extensive wildfires having occurred around this time (Kennett et al. 2008; Stich et al. 2008; Mahaney et al. 2010). Scott et al. (2010), however, oppose the idea of catastrophic wildfires having been impact induced during the early YD, noting that reports of glassy carbon spherules may actually be a misidentification of fungal sclerotia that were charred in lowintensity burning. Furthermore, the suggestion by Firestone et al. (2007) that this early YD wildfire episode was associated with a comet impact and a nuclear winter cooling is not supported by the glacial record. The high ammonium concentrations instead are seen to have occurred over a century after the beginning of the YD cooling and to have occurred during warm intervals that both preceded and followed the 12,837 yr BP ECM spike. This is seen most clearly in the NGRIP ice-core record presented in Figure 6 (Steffensen et al. 2008). The discovery that these biomass combustion indicators reach maximum values preferably during these 2 periods of climatic warming is consistent with the findings of Marlon et al. (2009) who report that wildfires historically tend to occur at times of climatic warming possibly due to an associated increase in climatic aridity. The occurrence of these wildfires may have temporarily eradicated the food supply for herbivores in some regions.

The 2 successive temperature maxima seen in the NGRIP core are spaced from one another by about 1 solar cycle period, which raises the question of whether the warmings may have been due to an increase in the Sun's total energy output during this period. Current observations show that solar irradiance is $0.1 \%$ higher at solar maximum as compared with solar minimum, which is far too small to have any significant climatic effect. However, 10 to $20 \%$ of this irradiance variation is in the UV, and UV output correlates positively with the level of solar flare activity. So if flare activity was 


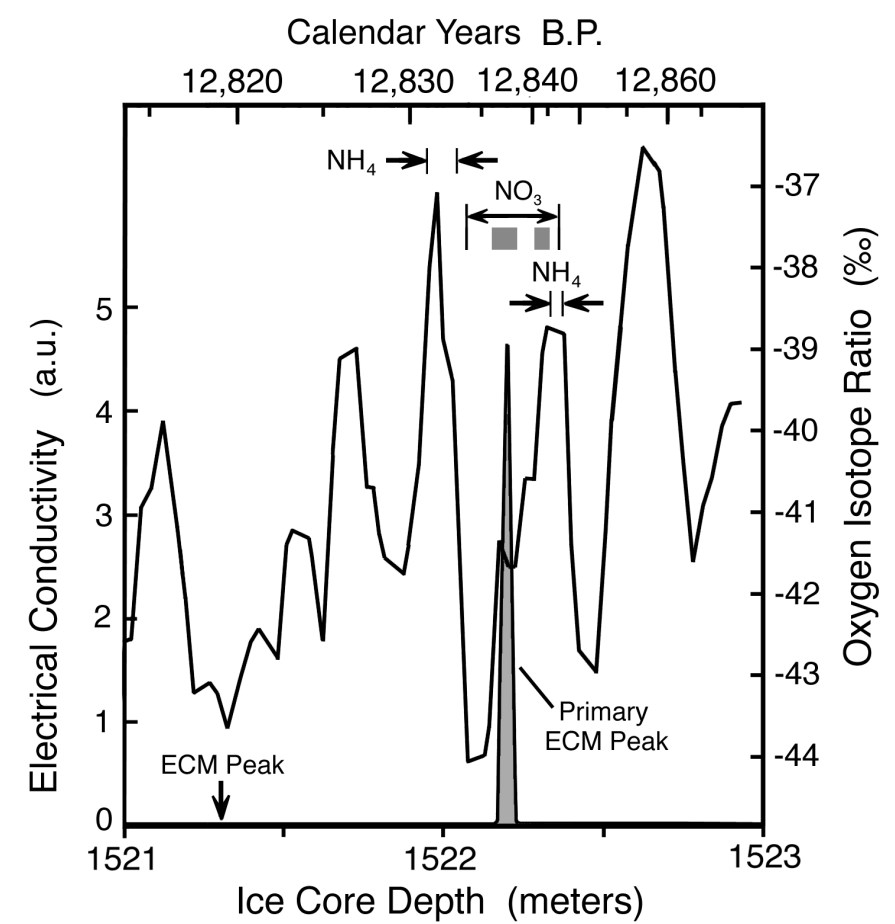

Figure 6 High-resolution oxygen isotope profile for the NGRIP Summit Greenland ice core (solid line) compared to relative electrical conductivity (lower shaded profile) (Steffensen et al. 2008). Horizontal arrows indicate periods of elevated $\mathrm{NH}_{4}$ and $\mathrm{NO}_{3}$ ion concentration. Shaded bands indicate intervals of nitrate ion depletion. Dating is based on the Cariaco Basin varve chronology.

substantially higher than current levels during this time, the solar constant could have increased sufficiently to have substantially impacted climate. Of the 2 climatic warmings, the one following the $12,837 \mathrm{yr}$ BP ECM event was the most extreme. The oxygen isotope ratio rose by almost $7 \%$ within less than $3 \mathrm{yr}$, bringing the climate in Greenland back to Allerød temperatures. This warming was more moderate in the subtropics as indicated in the Cariaco Basin profile. ${ }^{4}$

Condensation nuclei ions being produced in the stratosphere by the impacting solar cosmic rays would have formed stratospheric clouds, increasing the opacity of the stratosphere and reducing light transmission to the Earth's surface. This could explain why the NGRIP ice-core oxygen isotope profile shows a sudden cooling lasting about $2 \mathrm{yr}$ immediately after the $12,837 \mathrm{yr}$ BP acidity spike (Figure 6). Light occlusion from stratospheric clouds may have impaired the survival of plant life and been a contributing factor in the megafaunal extinction.

\footnotetext{
${ }^{4} \mathrm{~A}$ similar pattern of an initial cooling spike followed by a prolonged warming is also evident in the case of the ECM event seen at the end of the Younger Dryas (YD) at a depth of $1678.3 \mathrm{~m}$ in the GISP2 ice core (11,571 cal yr BP). This was the largest ECM spike to occur during the YD. It coincided with a 1-yr-long cooling, registered as a $-4 \%$ change in oxygen isotope ratio, and was immediately followed by a 14-yr warming. An almost equally large ECM spike registered 1 Hale solar cycle later (22 yr) coincided with an abrupt climatic cooling followed by the decade-long warming that ended the YD and heralded the beginning of the Holocene. This terminal event also appears to coincide with a small ${ }^{10} \mathrm{Be}$ deposition rate peak. This suggests that an overly active Sun may have played a significant role also in causing abrupt climatic change at the end of the ice age.
} 


\section{EXTRATERRESTRIAL DUST AND COLLAPSE OF THE CIRCUMTERRESTRIAL DUST CLOUD}

A solar proton event (SPE) intense enough to induce a partial collapse of the magnetosphere would likely have had a significant effect on the circumterrestrial dust cloud. Satellite and rocket observations have shown that the Earth is surrounded by a dust cloud extending radially outward from the Earth for a distance of $10^{5}$ to $10^{6} \mathrm{~km}$, or for up to 15 to 150 earth radii (Divari 1966, 1967; Tverskoi 1967; Senatorov 2000). Sunlight scattered from this dust is believed to account for at least $10 \%$ of the light of the zodiacal cloud (Divari 1965). Compared with interplanetary space, the number density of dust particles is estimated to be $10^{5}$-fold higher for particles in the radial size range 0.1 to 10 $\mu \mathrm{m}, 3000$-fold higher for particles having radii on the order of $100 \mu \mathrm{m}$, and tapering down to essentially no enhancement for 1-cm-sized meteoroids. It is estimated that dust particles may have residence times in this cloud for upwards of thousands of years.

The cloud acquires this dust from the local interplanetary environment and also from particles blown off the surface of the Moon by the impacting solar wind (Divari 1966). Dust grains in the interplanetary environment acquire an electrical charge through photoionization by solar UV and through encounters with background plasma electrons and ions (Sickafoose et al. 2000; Shukla 2001). Such charged grains are susceptible to being picked up by Earth's magnetosphere and magnetotail as the Earth orbits the Sun. Dust particles trapped in certain parts of this cloud could have been heated to their melting point by the cosmic-ray plasma of repeated SPE or CME impacts, hence turning some into cosmic spherules. Such cosmic-ray heating would have been greatest between 1 and 4 earth radii above the Earth's surface where the dust cloud's dense inner portion is intersected by the Earth's storm time radiation belts. A somewhat similar heating process has been proposed to account for the spherules found on the Moon (Mueller and Hinsch 1970).

Since the dust particles in the sheath have very low velocities relative to the Earth, their motions are dominated by the geomagnetic field. They would be particularly susceptible to movement of the geomagnetic field since the Lorentz force is stronger than gravity for particles in the mass range of $10^{-20}$ to $10^{-15} \mathrm{~g}$ ( $\mathrm{r}$ from 0.1 to $5 \mu \mathrm{m}$ ) (Alfven and Arrhenius 1979). The compression and subsequent partial collapse of the magnetosphere brought about by the arrival of the 12,837 cal yr BP super SPE and its associated coronal mass ejection (CME) could have jettisoned a large fraction of this dust into the Earth's stratosphere leaving the particles to settle to the Earth's surface over a period of months to years. Magnetic particles present in this dust cloud would have been particularly susceptible to transport.

The circumterrestrial dust cloud is estimated to presently contain a $10^{4}$ - to $10^{5}$-fold higher dust concentration than the interplanetary ambient. Figuring the interplanetary dust concentration to be on the order of $2 \times 10^{-22} \mathrm{~g} / \mathrm{cm}^{3}$, the sheath's dust mass concentration may currently reach $10^{-17} \mathrm{~g} / \mathrm{cm}^{3}$, with $10^{13} \mathrm{~g}$ being present in the inner portion of the cloud within $10^{5} \mathrm{~km}$ (15 earth radii) of the Earth's surface. If solar system cosmic dust concentrations were substantially higher at the end of the last ice age (LaViolette 1983, 1985, 2005), this potential cosmic dust source could have amounted to as much as $10^{15} \mathrm{~g}$.

The negative results reported by some research teams seeking evidence of extraterrestrial (ET) indicators in early YD sediments calls into question the existence of a uniformly distributed layer of homogenized debris as might be expected to come from a comet impact fireball. On the other hand, given that several groups have found ET markers in certain locales, the possibility remains that ET material may have been deposited nonuniformly, as might occur in the case of a dust sheath collapse. Since dust particles would have entered the atmosphere with low kinetic energy, they would have made a negligible contribution to the polar ice nitrate ion signal. 


\section{CONCLUSION}

Spurts of ${ }^{14} \mathrm{C}$ production evident in the Cariaco Basin varve record spaced at 22-yr solar cycle intervals likely record times of super-sized solar proton events (SPEs), some of which may have been intense enough to overpower and penetrate the magnetosphere. The largest of these ${ }^{14} \mathrm{C}$ spurts, which dates at 12,837 $\pm 10 \mathrm{yr} \mathrm{BP}$ in the Cariaco Basin record, is shown to correlate in time with a prominent short-duration acidity spike found in the Summit, Greenland ice-core record, which is positioned in the midst of prominent nitrate ion concentration maxima indicative of substantial atmospheric ionization by cosmic rays. Extrapolations based on the ${ }^{14} \mathrm{C}$ data suggest that the 12,837 cal yr BP SPE had about 125 times the fluence of the February 1956 SPE and was strong enough to deliver a ground-level radiation dose exceeding $3 \mathrm{~Sv}$ over a 2-day period. Radiation doses in excess of $6 \mathrm{~Sv}$ are projected if the associated solar storm main phase decrease had induced a collapse of the magnetosphere. This super SPE is proposed to have been the cause of the final disappearance of the Pleistocene megafauna. A super SPE occurring around 12,819 yr BP may have also contributed to the megafaunal demise. Smaller mammals and birds unprotected from the particle radiation would also have been at risk. Elevated levels of UV radiation resulting from destruction of the ozone layer would have posed an additional hazard. Cosmic dust from the circumterrestrial dust sheath injected into the stratosphere at the time of super SPE impact could account for the sporadic reports of ET indicators in early YD sediments and Greenland ice.

A definitive test of the solar super SPE hypothesis could be made by analyzing Greenland ice in the vicinity of the 1708.65 -m acidity spike to determine whether a large increase in ${ }^{10} \mathrm{Be}$ concentration occurred at that time. Additional analysis of platinum group elements in this portion of the ice core could check whether the proposed SPE may have been sufficiently strong to cause a collapse of the circumterrestrial dust sheath.

\section{REFERENCES}

Alfven H, Arrhenius G. 1979. Evolution of the Solar System. Washington, DC: NASA.

Alley RB, Shuman CA, Meese DA, Gow AJ, Taylor JC, Cuffey KM, Fitzpatrick JJ, Grootes PM, Zielinski GA, Ram M, Spinelli G, Elder B. 1997. Visual-stratigraphic dating of the GISP2 ice core: basis, reproducibility, and application. Journal of Geophysical Research 102(C12):26,367-81.

Baales M, Bittmann F, Kromer B. 1999. Verkohlte Bäume im Trass der Laacher See-Tephra bei Kruft (Neuwieder Becken). Ein Beitrag zur Datierung des Laacher See-Ereignisses und zur Vegetation der Alleröd-Zeit am Mittelrhein. Archäologisches Korrespondenzblatt 28:191-204.

Beer J, Andree M, Oeschger H, Siegenthaler U, Bonani G, Hofmann H, Morenzoni E, Nessi M, Suter M, Wölfli W, Finkel R, Langway Jr C. 1984. The Camp Century ${ }^{10} \mathrm{Be}$ record: implications for long-term variations of the geomagnetic dipole moment. Nuclear Instruments and Methods in Physics Research B 5(2): $380-4$.

Beer J. 2000. Long-term indirect indices of solar variability. Space Science Reviews 94(1-2):53-66.

Beets C, Sharma M, Kasse K, Bohncke S. 2008. Search for extraterrestrial osmium at the Allerød-Younger Dryas boundary. Fall AGU Meeting. Abstract \#V53A2150.

Creer KM, Anderson TW, Lewis CFM. 1976. Late quaternary geomagnetic stratigraphy recorded in Lake Erie sediments. Earth and Planetary Science Letters 31:37-47.

Dessler AJ, Parker EN. 1959. Hydromagnetic theory of geomagnetic storms. Journal of Geophysical Research 64:2239-59.

Dibb JE, Arsenault M, Peterson MC, Honrath RE. 2002. Fast nitrogen oxide photochemistry in Summit, Greenland snow. Atmospheric Environment 36(1516):2501-11.

Divari NB. 1965. Contribution of the circumterrestrial dust cloud to the brightness of the zodiacal light and Fcorona. Astronomicheskiy Zhurnal 42:645-652.

Divari NB. 1966. Charged dust particles in interplanetary space. Astronomicheskiy Zhurnal 43:192-7.

Divari NB. 1967. The cosmic dust cloud around the Earth. Soviet Astronomy 10:1017-30.

Dreschhoff GAM, Zeller EJ. 1994. 415-year Greenland ice core record of solar proton events dated by volcanic eruptive episodes. Institute of Tertiary-Quaternary Studies - TER-QUA Symposium Series 2:1-24.

Dubowski Y, Colussi AJ, Hoffmann MR. 2001. Nitrogen dioxide release in the $302 \mathrm{~nm}$ band photolysis of spray-frozen aqueous nitrate solutions: atmospheric implications. Journal of Physical Chemistry A 105(20):4928-32. 
Edwards WE. 1967. The Late Pleistocene extinction and the dimunition in size of many mammalian species. In: Martin PS, Wright Jr HE, editors. Pleistocene Extinctions: The Search for a Cause. New Haven: Yale University Press. p 141-54.

Epelman S, Hamilton DR. 2006. Medical mitigation strategies for acute radiation exposure during space flight. Aviation, Space, and Environmental Medicine 77:130-9.

Faith JT, Surovell T. 2009. Synchronous extinction of North America's Pleistocene mammals. Proceedings of the National Academy of Sciences (USA) 106: 20,641-5.

Finkel RC, Nishiizumi K. 1997. Beryllium 10 concentration in the Greenland ice sheet Project 2 ice core from 3-40 ka. Journal of Geophysical Research 102(C12): 26,699-706.

Firestone RB, West A, Warwick-Smith S. 2006. The $C y$ cle of Cosmic Catastrophes: How a Stone-Age Comet Changed the Course of World Culture. Rochester: Bear \& Co.

Firestone RB, West A, Kennett JP, Becker L, Bunch TE, Revay ZS, Schultz PH, Belgya T, Kennett DJ, Erlandson JM, Dickenson OJ, Goodyear AC, Harris RS, Howard GA, Kloosterman JB, Lechler P, Mayewski PA, Montgomery J, Poreda R, Darrah T, Que Hee SS, Smith AR, Stich A, Topping W, Wittke JH, Wolbach WS. 2007. Evidence for an extraterrestrial impact 12,900 years ago that contributed to the megafaunal extinctions and the Younger Dryas cooling. Proceedings of the National Academy of Sciences (USA) 104: 16,016-21.

Firestone RB, West A, Bunch TE. 2010. Confirmation of the Younger Dryas boundary (YDB) data at Murray Springs, AZ. Proceedings of the National Academy of Sciences (USA) 107:E105.

Foelsche T. 1974. Estimates of radiation exposure from solar cosmic rays in SST altitudes. NASA TM X71990.

Grayson DK. 1977. Pleistocene avifaunas and the overkill hypothesis. Science 196(4279):691-3.

Grayson DK, Meltzer DJ. 2003. A requiem for North American overkill. Journal of Archaeological Science 30(5):585-93.

Guilday JE. 1967. Differential extinction during latePleistocene and recent times. In: Martin PS, Wright Jr HE, editors. Pleistocene Extinctions: The Search for a Cause. New Haven: Yale University Press. p 121-40.

Haynes Jr CV. 2006. The Rancholabrean termination: sudden extinction in the San Pedro Valley, Arizona 11,000 B.C. In: Morrow JE, Gnecco C, editors. Paleoindian Archeology: A Hemispheric Perspective. Gainesville: University of Florida Press. p 139-63

Haynes Jr CV. 2008. Younger Dryas "black mats" and the Rancholabrean termination in North America. Proceedings of the National Academy of Sciences (USA) 105:6520-5.
Haynes Jr CV, Boerner J, Domanik K, Lauretta D, Ballenger J, Goreva J. 2010. The Murray Springs Clovis site, Pleistocene extinction, and the question of extraterrestrial impact. Proceedings of the National Academy of Sciences (USA) 107:4010-5.

Hays JD. 1971. Faunal extinctions and reversals of the Earth's magnetic field. Geological Society of America Bulletin 82:2433-47.

Hays JD, Opdyke ND. 1967. Antarctic radiolarea, magnetic reversals and climatic change. Science 158(3804):1001-11.

Hays JD, Saito T, Opdyke ND, Burckle L. 1969. Pliocene/Pleistocene sediments of the equatorial Pacific: their paleomagnetic biostratigraphic and climatic record. Geological Society of America Bulletin 80:1481-514.

Hua Q, Barbetti M, Fink D, Kaiser KF, Friedrich M, Kromer B, Levchenko VA, Zoppi U, Smith AM, Bertuch F. 2009. Atmospheric ${ }^{14} \mathrm{C}$ variations derived from tree rings during the early Younger Dryas. Quaternary Science Reviews 28(25-26):2982-90.

Hughen KA, Southon JR, Lehman S, Overpeck J. 2000. Synchronous radiocarbon and climate shifts during the last deglaciation. Science 290(5498):1951-4.

Isaksson E, Pohjola V, Jauhiainen T, Moore J, Pinglot JF, Vaikmäe R, van de Wal RSW, Hagen J-O, Ivask J, Karlöf L, Martma T, Meijer HAJ, Mulvaney R, Thomassen MPA, Van den Broeke M. 2001. A new icecore record from Lomonosovfonna, Svalbard: viewing the 1920-97 data in relation to present climate and environmental conditions. Journal of Glaciology 47(157):335-45.

Jackman CH, Frederick JE, Stolarski RS. 1980. Production of odd nitrogen in the stratosphere and mesosphere: an intercomparison of source strengths. Journal of Geophysical Research 85(C12):7495-505.

Jackman CH, Peters RD, Labow GJ, Fleming EL, Praderas CJ, Russell JM. 2001. Northern hemisphere atmospheric effects due to the July 2000 Solar Proton Event. Geophysical Research Letters 28(15):2883-6.

Jones AE, Weller R, Wolff EW, Jacobi HW. 2000. Speciation and rate of photochemical $\mathrm{NO}$ and $\mathrm{NO}_{2}$ production in Antarctic snow. Geophysical Research Letters 27(3):345-8.

Jones AE, Weller R, Anderson PS, Jacobi HW, Wolff EW, Schrems O, Miller H. 2001. Measurements of $\mathrm{NO}_{\mathrm{x}}$ emissions from the Antarctic snowpack. Geophysical Research Letters 28(8):1499-502.

Jull AJT, Haynes Jr V, Donahue D, Burr GS, Beck JW. 1999. Radiocarbon ages at Murray Springs, Arizona and the influence of climate change on Clovis man. In: Proceedings of the 3 rd Conference on ${ }^{14} \mathrm{C}$ and Archaeology. Lyons, France, 1998. Mémoires de la Société préhistorique française 26:339-43.

Kennett DJ, Kennett JP, West GJ, Erlandson JM, Johnson JR, Hendy IL, West A, Culleton BJ, Jones TL, Stafford Jr TW. 2008. Wildfire and abrupt ecosystem disrup- 
tion on California's Northern Channel Islands at the Allerød-Younger Dryas boundary (13.0-12.9 ka). Quaternary Science Reviews 27(27-28):2530-45.

Kurbatov A, Mayewski Pa, Steffensen JP, West A, Kennett DJ, Kennett JP, Bunch TE, Handley M, Introne DS, Que Hee SS, Mercer C, Sellers M, Shen F, Sneed SB, Weaver JC, Wittke JH, Stafford Jr TW, Donovan JJ, Xie S, Razink JJ, Stich A, Kinzie CR, Wolbach WS. 2010. Discovery of a nanodiamond-rich layer in the Greenland ice sheet. Journal of Glaciology 56: $747-57$.

LaViolette PA. 1983. Galactic explosions, cosmic dust invasions, and climatic change [PhD dissertation]. Portland: Portland State University.

LaViolette PA. 1985. Evidence of high cosmic dust concentrations in Late Pleistocene polar ice. Meteoritics 20:545-58.

LaViolette PA. 1987. Cosmic ray volleys from the Galactic center and their recent impact on the Earth environment. Earth, Moon, and Planets 37:241-86.

LaViolette PA. 1990 Galactic core explosions and the evolution of life. Anthropos 12:239-55.

LaViolette PA. 2005. Solar cycle variations in ice acidity at the end of the last ice age: possible marker of a climatically significant interstellar dust incursion. Planetary and Space Science 53:385-93.

Legrand MR, De Angelis M, Staffelbach T, Neftel A, Stauffer B. 1992. Large perturbations of ammonium and organic acids content in the Summit-Greenland ice core. Fingerprint from forest fires? Geophysical Research Letters 19(5):473-5.

Mahaney WC, Kalm V, Krinsley DH, Tricart P, Schwartz S, Dohm J, Kim KJ, Kapran B, Milner MW, Beukens R, Boccia S, Hancock RGV, Hart KM, Kelleherk B. 2010. Evidence from the northwestern Venezuelan Andes for extraterrestrial impact: the black mat enigma. Geomorphology 116(1-2):48-57.

Marlon JR, Bartlein PJ, Walsh MK, Harrison SP, Brown $\mathrm{KJ}$, Edwards ME, Higuera PE, Power MJ, Anderson RS, Briles C, Brunelle A, Carcaillet C, Daniels M, Hul FS, Lavoie M, Long C, Minckley T, Richard PJH, Scott AC, Shafer DS, Tinners W, Umbanhowar Jr CE, Whitlock C. 2009. Wildfire responses to abrupt climate change in North America. Proceedings of the National Academy of Sciences (USA) 106:2519-24.

Martin PS. 1967. Prehistoric overkill. In: Martin PS, Wright Jr HE, editors. Pleistocene Extinctions: The Search for a Cause. New Haven: Yale University Press. p 75-120.

McCabe JR, Boxe CS, Colussi AJ, Hoffmann MR, Thiemens MH. 2005. Oxygen isotopic fractionation in the photochemistry of nitrate in water and ice. Journal of Geophysical Research 110: D15310.

McCracken KG, Smart DF, Shea MA, Dreschhoff AM. 2001a. 400 years of large fluence solar proton events. Proceedings of the 27th International Cosmic Ray Conference 8:3209-12.
McCracken KG, Dreschhoff GAM, Zeller EJ, Smart DF, Shea MA. 2001b. Solar cosmic ray events for the period 1561-1994. 1. Identification in polar ice, 15611950. Journal Geophysical Research 106(A10): 21,585-98.

McManus JF, Francois R, Gherardi J-ML, Keigwin D, Brown-Leger S. 2004. Collapse and rapid resumption of Atlantic meridional circulation linked to deglacial climate changes. Nature 428(6985):834-7.

Mehringer Jr PJ. 1967. The environment of extinction of the Late Pleistocene megafauna in the arid southwestern United States. In: Martin PS, Wright Jr HE, editors. Pleistocene Extinctions: The Search for a Cause. New Haven: Yale University Press. p 247-66.

Melott AL, Thomas BC, Dreschoff G, Johnson CK. 2010. Cometary airbursts and atmospheric chemistry: Tunguska and a candidate Younger Dryas event. Geology 38(4):355-8.

Meltzer DJ, Mead JI. 1985. Dating late Pleistocene extinctions: theoretical issues, analytical bias, and substantive results. In: Mead J, Meltzer D, editors. Environment and Extinction: Man in Late Glacial North America. Orono: Center for the Study of Early Man, University of Maine. p 145-73.

Meltzer DJ. 2004. Peopling of North America. In: Gillespie AR, Porter SC, Atwater BF, editors. The Quaternary Period in the United States. Amsterdam: Elsevier. p 539-63.

Miller WE. 1987. Mammut Americanum: Utah's first record of the American mastodon. Journal of Paleontology 61:168-83.

Mueller G, Hinsch GW. 1970. Glassy particles in lunar fines. Nature 228(5268):254-8.

Muscheler R, Beer J, Wagner G, Finkel RC. 2000. Changes in deep-water formation during the Younger Dryas event inferred from ${ }^{10} \mathrm{Be}$ and ${ }^{14} \mathrm{C}$ records. $\mathrm{Na}$ ture 408(6812):567-70.

Napier WM. 2010. Palaeolithic extinctions and the Taurid complex. Monthly Notices of the Royal Astronomical Society 405(3):1901-6.

Paquay FS, Goderis S, Ravizza G, Vanhaeck F, Boyd M, Surovell TA, Holliday VT, Haynes Jr CV, Claeys P. 2009. Absence of geochemical evidence for an impact event at the Bølling-Allerød/Younger Dryas transition. Proceedings of the National Academy of Sciences (USA) 106(51):21,505-10.

Parkin DW, Sullivan RAL, Andrews JN. 1977. Cosmic spherules as rounded bodies in space. Nature 266(5602):555-7.

Ram M, Stolz M. 1999. Possible solar influences on the dust profile of the GISP2 ice core from Central Greenland. Geophysical Research Letters 26(8):1043-6.

Ram M, Stolz M, Koenig G. 1997. Eleven year cycle of dust concentration variability observed in the dust profile of the GISP2 Ice core from Central Greenland: possible solar cycle connection. Geophysical Research Letters 24(19):2359-62. 
Rasmussen SO, Seierstad IK, Andersen KK, Bigler M, Dahl-Jensen D, Johnsen SJ. 2008. Synchronization of the NGRIP, GRIP, and GISP2 ice cores across MIS 2 and palaeoclimatic implications. Quaternary Science Reviews 27(1-2):18-28.

Reid GC, Isaksen ISA, Holzer TE, Crutzen PJ. 1976. Influence of ancient solar-proton events on the evolution of life. Nature 259(5540):177-9.

Rietmeijer FJM. 2006. Natural Fullerenes and Related Structures of Elemental Carbon. Volume 6. Dordrecht: Springer. p 123-44.

Schaefer BE, King JR, Deliyannis CP. 2000. Superflares on ordinary solar-type stars. Astrophysical Journal 529:1026-30.

Scott AC, Pinter N, Collinson ME, Hardiman M, Anderson RS, Brain APR, Smith SY, Marone F, Stampanoni M. 2010. Fungus, not comet or catastrophe, accounts for carbonaceous spherules in the Younger Dryas "impact layer." Geophysical Research Letters 37: L14302, doi:10.1029/2010GL043345.

Senatorov VN. 2000. On the possible existence of radiation dust belts in near-Earth space. Cosmic Research 38:612-5.

Shumilov OI, Kasatkina EA, Henriksen K, Vashenyuk EV. 1996. Enhancement of stratospheric aerosols after solar proton event. Annales Geophysicae 14(11): 1119-23.

Shukla PK. 2001. A survey of dusty plasma physics. Physics of Plasmas 8:1791-803.

Sickafoose AA, Colwell JE, Horányi M, Robertson S. 2000. Photoelectric charging of dust particles in vacuum. Physics Review Letters 84(26):6034-7.

Skeels MA. 2002. The mastodons and mammoths of Michigan. Michigan Academician 34:254.

Slaughter BH. 1967. Animal ranges as a clue to LatePleistocene extinction. In: Martin PS, Wright Jr HE, editors. Pleistocene Extinctions: The Search for a Cause. New Haven: Yale University Press. p 155-67.

Steffensen JP, Andersen KA, Bigler M, Clausen HB, Dahl-Jensen D, Fischer H, Goto-Azuma K, Hansson M, Johnsen SJ, Jouzel J, Masson-Delmotte V, Popp T, Rasmussen SO, Röthlisberger R, Ruth U, Stauffer B, Siggaard-Andersen M-L, Sveinbjörnsdóttir ÁE, Svensson A, White JWC. 2008. High-resolution Greenland ice core data show abrupt climate change happens in few years. Science 321(5889):680-4.

Stich A, Howard G, Kloosterman JB, Firestone RB, West A, Kennett JP; Kennett DJ, Bunch TE, Wolbach WS. 2008. Soot as evidence for widespread fires at the Younger Dryas onset (YDB; $12.9 \mathrm{ka}$ ). American Geophysical Union, Fall Meeting 2008, abstract \#PP13C1471.

Stocker TF, Wright DG. 1996. Rapid changes in ocean circulation and atmospheric radiocarbon. Paleoceanography 11:773-95.

Stuiver M, Kra RS. 1986. High-precision calibration of the radiocarbon time scale, AD 1950-500 BC. Radiocarbon 28(2B):805-38.
Stuiver M, Grootes PM. 2000. GISP2 oxygen isotope ratios. Quaternary Research 53(3):277-84.

Surovell TA, Holliday VT, Gingerich JAM, Ketron C, Haynes Jr CV, Hilman I, Wagner DP, Johnson E, Claeys P. 2009. An independent evaluation of the Younger Dryas extraterrestrial impact hypothesis. Proceedings of the National Academy of Sciences (USA) 106(43):18,155-8.

Taylor KC, Hammer CU, Alley RB, Clausen HB, DahlJensen D, Gow AJ, Gundestrup NS, Kipfstuh J, Moore JC, Waddington ED. 1993. Electrical conductivity measurements from the GISP2 and GRIP Greenland ice cores. Nature 366(6455):549-52.

Taylor KC, Mayewski PA, Twickler MS, Whitlow SI. 1996. Biomass burning recorded in the GISP2 ice core: a record from eastern Canada? The Holocene 6(1):1-6.

Tian H, Schryvers D, Claeys P. 2011. Nanodiamonds do not provide unique evidence for a Younger Dryas impact. Proceedings of the National Academy of Sciences (USA) 108:40-4.

Tverskoi BA. 1967. The influence of corpuscular radiation on the circumterrestrial cloud. Soviet Astronomy 10:1031-3.

Usoskin IG, Solanki SK, Kovaltsov GA, Beer J, Kromer B. 2006. Solar proton events in cosmogenic isotope data. Geophysical Research Letters 33(8): L08107.

Vereshchagin NK. 1967. Primitive hunters and Pleistocene extinction in the Soviet Union. In: Martin PS, Wright Jr HE, editors. Pleistocene Extinctions: The Search for a Cause. New Haven: Yale University Press. p 365-98.

Wagner G, Beer J, Masarik J, Muscheler R, Kubik PW, Mende W, Laj C, Raisbeck GM, Yiou F. 2001. Presence of the solar de Vries cycle ( 205 years) during the last ice age. Geophysical Research Letters 28(2): 303-6.

Waters MR, Stafford Jr TW. 2007. Redefining the Age of Clovis: implications for the peopling of the Americas. Science 315(5815):1122-6.

Wolff EW. 1995. Nitrate in Polar Ice. New York: Springer-Verlag.

Yang Q, Mayewski PA, Whitlow SI, Twickler MS, Morrison MC, Talbot RW, Dibb JE, Linder E. 1995. Global perspective of nitrate flux in ice cores. Journal of Geophysics Research 100(D3):5113-21.

Zeller EJ, Dreschhoff GAM. 1995. Anamalous nitrate concentrations in polar ice cores-Do they result from solar particle injections into the polar atmosphere? Geophysical Research Letters 22(18):2521-4.

Zook HA, Hartung JB, Storzer D. 1977. Solar flare activity: evidence for large-scale changes in the past. Icarus 32:106-26.

Zook HA. 1980. On lunar evidence for a possible large increase in solar flare activity $\sim 2 \times 10^{4}$ years ago. In: Peppin R, Eddy J, Merril R, editors. In: The Ancient Sun: Fossil Record in the Earth, Moon and Meteorites. New York: Pergamon Press. p 245-66. 